\title{
Cardiac troponin biosensors: where are we now?
}

This article was published in the following Dove Press journal: Advanced Health Care Technologies

\author{
Sayali Upasham \\ Ambalika Tanak \\ Shalini Prasad \\ Department of Biomedical \\ Engineering, The University of Texas at \\ Dallas, Richardson, TX, USA
}

\begin{abstract}
Acute myocardial infarction (AMI) is one of the leading causes of death among the cardiovascular diseases. Of several biomarkers used for detection, increased levels of cardiac troponins have proved to be significant in diagnosing AMI. This has motivated researchers in the field to develop point-of-care biosensors for rapid detection of an episode of AMI. Over the years, various detection techniques have emerged for the estimation of cardiac troponins. This review focuses on summarizing various biosensing methods, including optical, electrochemical, and acoustic techniques, for the detection of cardiac troponins.
\end{abstract}

Keywords: cardiac troponin, acute myocardial infarction, optical, electrochemical, SPR, SERS

\section{Introduction}

Myocardial infarction is a disease characterized by the death of cardiac myocytes, which is due to an imbalance between the demand for blood by the cardiac tissue and the supply of blood. The symptoms of this perfusion imbalance or ischemia can be misdiagnosed as gastrointestinal or pulmonary disorders because of their atypical clinical presentation. This leaves the patient vulnerable to cardiac arrest, which is life threatening. Thus, in patients with these symptoms, there is a need to consider the possibility of acute myocardial infarction (AMI), conduct tests, and rule it out if possible. ${ }^{1}$

Before cardiac troponin sensors were developed, patients with acute chest pains were diagnosed with AMI using only an electrocardiogram (ECG). Since this technique had only a $50 \%$ accuracy in detecting AMI, patients would often be misdiagnosed. Despite its lack of sensitivity, ECG is still used as a validation test to identify patients with myocardial infarction, but nowadays it is coupled with testing for biomarkers to facilitate proper treatment. Researchers have discovered that the levels of cardiac troponins have a significant correlation with the onset of AMI and can be potential biomarkers for the disease. These troponins, namely cardiac troponin $\mathrm{T}$ (cTnT) and cardiac troponin I (cTnI), are a measure of the damage to the cardiac myocytes. AMI is characterized by damage to the cardiac myocytes, which causes the troponins to enter the circulation, where they can be detected using immunological assays. This led to the development of bedside troponin T and I testing methods. ${ }^{2}$ cTnT and cTnI are deemed gold standards for the diagnosis of AMI as their levels in serum indicate damage to the cardiac myocytes. There was a need to set a threshold for diagnostically relevant levels of cardiac troponins. The clinical cut-off level of cTnT indicative of AMI is a concentration greater than $0.01 \mathrm{ng} / \mathrm{mL}$ or $10 \mathrm{pg} / \mathrm{mL}$. The clinical cut-off for $\mathrm{cTnI}$ is $0.03 \mathrm{ng} / \mathrm{mL}$ or $30 \mathrm{pg} / \mathrm{mL}$. The key reference range for any troponin assays
Correspondence: Shalini Prasad 800 W. Campbell Road, BSB II. University of Texas, Dallas, Richardson, TX 75080, USA

Tel +l 9728834247

Email Shalini.Prasad@utdallas.edu
Advanced Health Care Technologies 2018:4 I-13

(c) (i) (8) ๑ 2018 Upasham et al. This work is published and licensed by Dove Medical Press Linited. The full terms of this license are avalable at https://www.dovepres.com/term. Dovepress f 1 in $\nabla$ http://dxdoi. 
to be implemented in the clinical environment is dependent on its 99th percentile reference limit and its coefficient of variation at the limit of detection (LOD). According to the recommendations of the National Academy of Clinical Biochemistry, clinical testing of serum samples for cardiac biomarkers should be made available with a turnaround time of less than 1 h. ${ }^{3,4}$

Studies introduced at the 2016 European Society of Cardiology Congress used high-sensitivity assays as an alternative approach for the diagnosis of AMI within $3 \mathrm{~h}$ of an episode of AMI. The study by Neumann et al discusses adopting a $1 \mathrm{~h}$ protocol for a cardiac troponin assay to triage patients with AMI. ${ }^{5}$ A $1 \mathrm{~h}$ algorithm coupled with two measurements of cardiac troponin is used for the accurate diagnosis of non-STsegment elevation myocardial infarction. The final diagnosis is made using a cTnT assay with electrocardiography, cardiac imaging, and coronary angiography. This study was validated using 4009 patients with an eclectic selection of medical history. Using high-sensitivity troponin assays and proper cut-off levels, it is possible to diagnose and monitor AMI in less than 3-4 h after the onset of chest pain.,

The rapid bedside testing method for cTnI and cTnT, discussed earlier in this section, used chemiluminescence as a method of detection using the streptavidin molecule. However, it required $10 \mathrm{~mL}$ of the patient's blood and was conducted in a separate laboratory in the hospital, which was a time-consuming process. ${ }^{2}$ Shortly after that, the Cardiac Troponin T rapid test (TROPT ${ }^{\circledR}$, Heidelberg, Germany) was developed, which uses strips to detect the cardiac troponin levels of patients already diagnosed with AMI. ${ }^{13}$ This test strip, based on a sandwich enzyme-linked immunosorbent assay (ELISA) technique, is sensitive to levels of cTnT above a concentration of $0.64 \mathrm{ng} / \mathrm{mL}$. Keller et al studied the accuracy of using troponin assays for the diagnosis of AMI. They conducted a clinical study involving patients who had elevated troponin from causes other than a coronary origin. The biomarkers selected for this study were analyzed as a function of the onset of chest pain. The results of the study suggested that a single value of the level of troponin I which is greater than the reference value is an accurate indicator of myocardial infarction. When coupled with onset of chest pain as a factor, the study concluded that measurement of troponin I level within $3 \mathrm{~h}$ after admission for chest pain has a $100 \%$ rate of detection of AMI. ${ }^{7}$ In 2015, Shah et al identified the threshold for cardiac troponin I in patients with suspected coronary syndrome and a low risk of AMI. A troponin concentration of less than $5 \mathrm{ng} / \mathrm{mL}$ with a negative predictive value of $99.5 \%$ was the threshold below which patients with suspected acute coronary syndrome could be discharged safely with very low risk of AMI. However, this study needs to be assessed further in a clinical setting to be applied in clinical routine practice. ${ }^{3}$ In a routine clinical setting, however, the cut-off level for cTnI is $10 \mathrm{pg} / \mathrm{mL}$ and for cTnT is $30 \mathrm{pg} / \mathrm{mL}$. With further development, we can increase the threshold and safely reduce the cost of treating patients for AMI when they are at minimum risk.

cTnI is a more accurate biomarker for the evaluation of cardiomyocyte damage as the levels are strongly correlated with cardiac injury, whereas cTnT is reported to be elevated in patients with chronic renal failure and on hemodialysis, not associated with cardiac injury. The second generation antibody for cTnT was developed after observing cross-reactivity with the antibody used in the first generation ELISA. This antibody displays better specificity than the first generation antibody. ${ }^{8}$ There have been several reports on improved assays for cTnT, one of which used a cardiac-specific monoclonal antibody for cTnT. Since the publication of this report in 1997, the cTnT assays have improved with the use of highly specific cTnT antibodies. ${ }^{9}$

Studies performed outside the USA have generally demonstrated that incorporating the results of high-sensitivity troponin tests speeds up the triage of patients with suspected acute coronary syndrome, although an Australian study published in 2016 failed to show major changes in clinical management or outcomes when a high-sensitivity troponin $\mathrm{T}$ assay was used. ${ }^{10}$ The newer high-sensitivity troponin assays overcome some of the limitations of traditional tests. One of the major challenges of conventional troponin methods in the setting of AMI is the fact such assays are frequently negative at first draw and require hours before they become abnormal. Highly sensitive troponins provide substantial advantages over conventional troponin assays in that they allow for more rapid detection of cardiomyocyte necrosis and at an earlier time-point. High-sensitivity assays are also able to rule out AMI at the first blood draw if the values are very low and are accompanied by other "normal" clinical characteristics. Hence, the use of highly sensitive troponin assays will be a paradigm shift in the assessment of AMI. The availability of highly sensitive troponin assays will have a beneficial impact on clinical practice, as these assays are helpful both in evaluating patients with chest pain and for triaging patients who may be at risk of other cardiovascular morbidities that do not involve ischemic heart disease.

A major breakthrough came with the commercialization of troponin-sensing devices by companies including Abbott and Roche, as summarized in Table 1. The pitfalls of these sensors are the cost of detection and their ability to detect only a single analyte. Hence, there was a need to develop 
Table I Summary of commercially available troponin detection technologies

\begin{tabular}{|c|c|c|c|c|}
\hline Commercially available troponin assays & $\begin{array}{l}\text { 99th percentile } \\
\text { cut-off }(\mathrm{ng} / \mathrm{mL})\end{array}$ & Time & Cost (USD) & Volume \\
\hline \multicolumn{5}{|l|}{ CTnT } \\
\hline Elecsys, third generation (Roche, Basel, Switzerland) & 0.01 & $60 \mathrm{~min}$ & 31,148 & $\mathrm{I} 50 \mu \mathrm{L}$ \\
\hline \multicolumn{5}{|l|}{ cTnl } \\
\hline i-STAT (Abbott Point of Care, Princeton, NJ, USA) & 0.08 & $10 \mathrm{~min}$ & 420 & $17 \mu \mathrm{L}$ \\
\hline ACS: I 80 (Bayer, Leverkusen, Germany) & 0.07 & $24 \mathrm{~h}$ & 1,200 & $10 \mathrm{~mL}$ \\
\hline Dimension Vista (Siemens, Munich, Germany) & 0.05 & $10 \mathrm{~min}$ & 278,000 & $20 \mu \mathrm{L}$ \\
\hline Architect (Abbott, Princeton, NJ, USA) & 0.04 & $10 \mathrm{~min}$ & 19,000 & $62 \mu \mathrm{L}$ \\
\hline
\end{tabular}

Abbreviations: CTnT, cardiac troponin T; cTnl, cardiac troponin I.

ultrasensitive multianalyte systems for diagnosing AMI which use low analyte volume at a lower cost point.

After a typical episode of AMI, the levels of these cardiac troponins increase from $0.04 \mathrm{ng} / \mathrm{mL}$, which is the normal reference limit indicating some damage, to greater than $1.4 \mathrm{ng} / \mathrm{mL}$, which is high enough to be detected in blood using various biosensors. ${ }^{11,12}$ Thus, the focus shifted toward troponin-based biosensors, which proved to be more efficient and faster methods for the diagnosis of AMI. ${ }^{13}$ As the troponin detection technology developed, the sensors became more sensitive, with lower limits of detection, became cheaper, and had high specificity for cardiac troponins, showing high cross-reactivity with skeletal troponins.

\section{Development of technologies}

Cardiac troponin sensors are widely used to detect and quantify the levels of cardiac troponin present in patients. These sensors had previously been highly invasive, time consuming, and inaccurate. Current techniques focus on being minimally invasive and rapid, and have lower limits of detection. In this review, three major techniques are summarized, based on their transduction mechanism, namely electrochemical, optical, and acoustic-based sensors. Electrochemical sensors are further divided into impedimetric, amperometric, potentiometric, and conductance-based sensors. Optical sensors include fluorescence- and chemiluminescence-based biosensors, surface-enhanced Raman spectroscopy (SERS), and surface plasmon resonance (SPR)-based sensors. Acoustic wave-based sensors have two subcategories, quartz crystal microbalance (QCM)-based and surface acoustic wave (SAW)-based sensors. A schematic representation of the various types of sensors is given in Figure 1.

\section{Current technologies \\ Electrochemical sensors}

Electrochemical sensors are divided into impedimetric, amperometric, potentiometric, and conductance-based

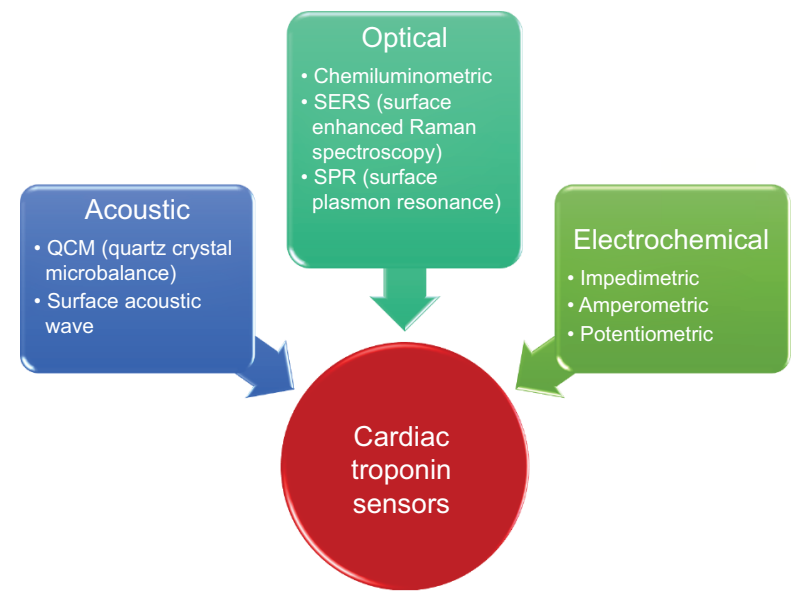

Figure I Overview of techniques used for cardiac troponin sensing.

sensors. These sensors work on the principle of change in the current, impedance, or potential difference when certain immunoreactions take place on the surface of the electrode of the sensor. Hence, these biosensors use various biomolecules as detection probes, such as enzymes, DNA, nucleic acid, and metabolites. Electrochemical sensors are robust and provide detection in real time. They have a low production cost, can be easily miniaturized for point-of-care diagnostics, and are easy to use. They offer high sensitivity, selectivity, and reliability. They can be fabricated using a variety of conducting substrates. Reviews on cardiac troponin sensors have found that they use a very low analyte volume for detection. ${ }^{78}$

The working mechanism of a basic troponin sensor is illustrated in Figure 2.

\section{Impedimetric sensors}

Impedimetric sensors measure changes in the impedance value when a potential is applied to the electrode. When an electrolyte is present over the surface-modified impedimetric sensor, polarization is observed on application of a potential to the electrode and charges migrate to the surface of the electrode to form an electric double layer. This double 


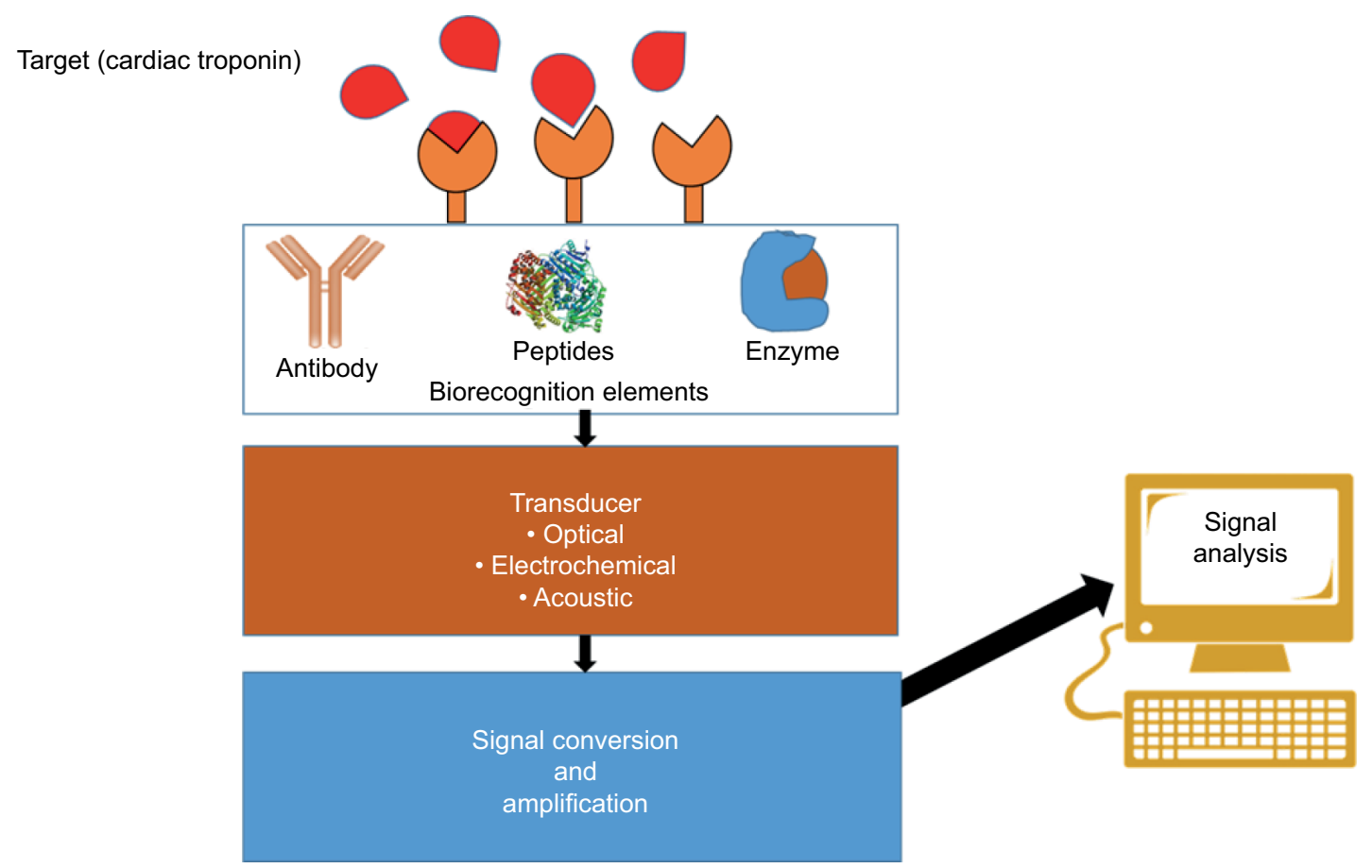

Figure 2 Working mechanism of cardiac troponin biosensors.

layer is a pocket of charges which is modulated when the antigen binds to the detecting antibody on the surface of the electrode. The antibody is immobilized on the surface of the electrode using cross-linking polymeric molecules such as dithiobis(succinimidyl propionate) (DSP) and 3,3'-dithiobi s(sulfosuccinimidyl propionate) (DTSSP). These molecules have a thiol group at one end, which helps in binding to the gold electrode, and a CO-NHS bond at the other end. On encountering an antibody, the bond breaks to form an amine linkage with the antibody. Various other linkers, such as (3-aminopropyl)triethoxysilane (APTES), are used according to the substrate and the material of the electrode. ${ }^{14-16}$ One such example is the zinc oxide $(\mathrm{ZnO})$ nanosensor developed by Radha Shanmugama et al. This multiplexed nanosensor with $\mathrm{ZnO}$ nanorods uses label-free electrochemical detection methods such as electrochemical impedance spectroscopy (EIS) to detect levels of cTnT and $\mathrm{cTnI}$ in human serum. It uses an immunological assay, which involves an $\alpha$-cTnT antibody coupled with a thiol linker bound to the $\mathrm{ZnO}$ nanorod electrodes present on a flexible substrate. This sensor has anti-cTnI antibodies attached to the other working electrode, thus making multiplexing possible, and it detects the antigens in the picogram range in human serum. ${ }^{17}$ Similarly, in 2016, Kazemi et al constructed a sensitive, label-free troponin biosensor using porous graphene oxide as the substrate for immobilization. Detection took place by measuring the change in impedance upon binding of the target. The LOD was $0.07 \mathrm{ng} / \mathrm{mL}$, with a wide dynamic range of $0.1-10 \mathrm{ng} /$ $\mathrm{mL}$, for $\mathrm{cTnI} .{ }^{18}$ The Clinical Laboratory and Standards Institute defines the LOD as the minimum concentration of the analyte at which detection occurs. It helps in measuring the sensitivity of the sensor and determines the lower limit of the dynamic range over which the sensor operates. ${ }^{19}$ Zuo et al demonstrated a molecularly imprinted polymer (MIP)-based electrochemical biosensor for troponins. They used a technique called electropolymerization, which is simple and cost effective, and gives the sensor good stability. For improved sensitivity, a glassy carbon electrode was used. The detection time was $5 \mathrm{~min}$, with an LOD of $0.027 \mathrm{nM}$, for cTnI. ${ }^{20}$

\section{Amperometric sensors}

These sensors work on the same principle of electrochemical organization as impedimetric sensors, where there is an immobilized antibody on the surface of the electrode. However, changes in current are measured instead of impedance. There is also a secondary antibody which is labeled with a chemical mediator. This chemical mediator or redox probe helps in quantifying the changes in the current generated at the working electrode, which provides information on the binding dynamics of the antigen and detecting antibody after a fixed potential bias has been applied to the electrode. The current changes are calculated relative to a reference 
electrode. Cyclic voltammetry is the most widely used signal detection technique for amperometric sensors. Carbon nanotubes (CNTs) are good candidates for sensing electrodes because of their versatile electrochemical properties, such as good electrical conductance, mechanical strength, and their ability to be incorporated with other materials. Moreover, their high electron transport rate helps to increase the reaction rate of many immunochemical reactions, thus enhancing the sensitivity and performance of the sensor. The sensor developed by Gomes-Filho et al immobilizes cTnT antibodies on a nanostructured gold electrode. This nanostructured electrode includes modified CNTs combined with electroactive conjugated polymers. These polymers act as charge promoters between the CNT and the electrolyte solution. Specifically, in their paper they used polyethyleneimine to bind to carboxylated CNTs. ${ }^{21}$

In a 2017 study, graphene quantum dots (GQDs) and polyamidoamine (PAMAM)-modified gold electrodes were used for the detection of cTnI levels in human serum. The LOD for this sensor is $20 \mathrm{fg} / \mathrm{mL}$. The main detection methods used are cyclic voltammetry and differential pulse voltammetry. ${ }^{12}$ PAMAM dendrimers have also been used with a 3,3',5,5'-tetramethyl benzidine-modified 6-mercaptohexanoic acid self-assembled monolayer (SAM) on a gold electrode for detection of cardiac troponins. These electrodes have an LOD of about $11.7 \pm 0.62 \mathrm{fM}$. These dendrimer-based sensors have a high sensitivity owing to the presence of branches, which increase the number of conjugation sites for the cTnI antibody and enhance the stability of the detection probe by covalent immobilization of the antibody. ${ }^{22}$

A commercially available immunoassay-based amperometric sensor is the i-STAT handheld, developed by Abbott Point of Care (Princeton, NJ, USA). It uses $17 \mu \mathrm{L}$ of the patient's whole blood and a disposable cartridge, and reports the level of cTnI within a few minutes. This test is used by clinicians for diagnosing patients with AMI and for providing a prognosis for current patients. The device detects $\mathrm{cTnI}$ in the range of $0-50 \mathrm{ng} / \mathrm{mL}$ and the normal physiological range is $0-0.08 \mathrm{ng} / \mathrm{mL}$. These wireless, handheld devices are widely used in hospitals across the USA as a point-of-care testing device for the detection of cTnI. ${ }^{23}$

\section{Potentiometric sensors}

Potentiometric sensors measure the potential difference between two electrodes separated by a semi-permeable membrane; alternatively, the potential difference can be measured from two electrodes when there is no current flowing between them. Potentiometric devices sense the difference in potential caused by changes in $\mathrm{pH}$ or redox reactions taking place on the surface of the electrode. The difference arises from the interaction between the immobilized capture probe and the antigen at the electrode-electrolyte interface; it can also result from chemisorption on the substrate molecules on the electrode's surface. The change determines the extent of binding of the antigen to the capture probe. These sensors are further classified into $\mathrm{pH}$ electrode-based glass ion-selective electrodes (ISEs), solid-state ion-selective field-effect transistors (ISFETs), and light-addressable potentiometric sensors (LAPSs). Field-effect transistor sensors are a modified version of the ISE type and are preferred for immunosensing. An example of an ISFET sensor used for detection of cardiac troponin is the polypyrrole-coated sensor developed by researchers in Cambridge, UK. ${ }^{24}$ The novelty of the sensor lies in the immunoseparation performed during the measurement and the polypyrrole layer grown on the surface of the electrode. This layer is polymerized using a potentiodynamic electropolymerization method, which makes the sensor robust and enhances its sensitivity. The potential difference is due to the interaction of the receptor-target complexes formed on the polypyrrole layer on the surface of the electrode. The researchers use an external labeling probe, i.e. the horseradish peroxidase (HRP) and $o$-phenylenediamine dihydrochloride system. Change is proportional to the number of cTnI molecules binding to the cTnI monoclonal antibodies immobilized on the polypyrrole layer. The assay takes about 5-20 min. The sensor is ultrasensitive for a wide range of immunoassays with large or medium-sized analytes owing to the polymerized layer.

\section{Conductance-based sensors}

Conductance-based sensors detect biomarkers based on changes in the value of conductance of the solution. Initially, a set voltage is applied to the sensor, which is a microfluidic channel coated with detection molecules such as antibodies or specific proteins, which generates a baseline current. This baseline current sets up the initial values from which the changes in conductivity can be measured. The bioanalyte, ideally a body fluid such as serum or blood containing the antigen specific for the antibody, is then flowed across the channel. Successful binding between the detection molecule and the antibody leads to a significant change in the amount of current required for detection. This is interpreted as a measure of conductance of the solution. Chua et al reported on the manufacture of a silicon nanowire-based sensor, which works on the same principle. The device is calibrated to detect cTnT levels in human serum in the range of $1 \mathrm{ng} / \mathrm{mL}$ to $1 \mathrm{fg} / \mathrm{mL}$. The Debye length is an 
important factor in evaluating the performance of the device. This length indicates the amount of screening of charges that occurs when there is a buffer involved with a low salt concentration. Since the salt concentration may affect the stability of the detection protein, it is important to measure the Debye length to confirm whether it can be detected by the sensor. ${ }^{25}$

\section{Optical sensors}

Optical biosensors detect changes in frequency of the input light, or changes in phase or polarization caused by biorecognition processes. They are typically classified under categories such as fluorescence, colorimetric, luminescence, and SPR sensors. ${ }^{26}$

\section{Fluorescence-based biosensors}

The earliest known fluorescence-based biosensor was developed in 1941 by Coons et al. ${ }^{27}$ In this biosensor, the biorecognition element or target analyte is labeled with a fluorescent tag, such as a dye or probe, and the intensity of fluorescence indicates the binding of the target molecule. An advance in cardiac troponin biomarker detection in the form of a fluorescence biosensor was reported by Kar et al. ${ }^{28}$ This group developed a point-of-care biosensor using $\mathrm{TiO}_{2}$ nanotube arrays.

Although fluorescence-based biosensors achieve high sensitivity, their major disadvantage lies in the tedious labeling process. Furthermore, it is difficult to control the fluorescence signal emitted from the amount of fluorophore on each molecule, making quantitative analysis difficult. ${ }^{29}$ In view of this, ellipsometry-based optical sensors are sometimes preferred.

A direct assay-based silicon optical sensor has also been developed. This sensor has a dielectric spin-coated on top of a silicon substrate, which is then functionalized to be specific to cTnI for its detection in human serum. An SAM of dextran is grown over the detection surface to increase the output by maximizing the available binding sites. However, the LOD of these sensors, at around $0.01 \mathrm{ng} / \mathrm{mL}$ for $\mathrm{cTnI}$ in human serum, is lower than that of their electrochemical counterparts. A major disadvantage is that these sensors cannot detect the cTnI levels in pure serum. All of the values were extrapolated from data obtained from $10 \%$ diluted serum. ${ }^{30}$

Photoelectrochemical sensors work in the same way as immunosensors; however, they have a photoresponsive component in addition to the basic immunosensing element. The anti-cTnI is covalently bound to the electrode surface and the response is checked by exciting it with laser light. The output is a photocurrent, which corresponds to the logarithmic concentration of the antigen (cTnI). A decrease in the photocurrent occurs as soon as there is antibody-antigen conjugation. In this study, the researchers used a redox probe (ascorbic acid) for detection. Thus, this sensor needs labeling; in addition, the LOD is around $1.756 \mathrm{pg} / \mathrm{mL}$, which is high compared with other sensors. ${ }^{31}$

\section{Calorimetric assays (chemiluminometric biosensors)}

Calorimetric immunoassays work on the principle of detecting the presence of the target analyte by measuring the amount of light absorbed by the chromogenic reagent, corresponding to a specific wavelength. The most popular and widely used calorimetric assay is the ELISA. This works on the principle of the sandwich immunoassay, where the antigen is captured by primary antibody followed by binding of secondary enzyme-linked antibody. The target analyte is detected by evaluating the amount of conjugated enzyme activity produced by the product. ${ }^{32}$ Using this principle, a chemiluminometric signal produced by HRP is most widely used to build a colorimetric assay. ${ }^{33}$ In 2009, Cho et al developed an ELISA-on-chip biosensor based on cross-flow chromatography for detection of cTnI. ${ }^{34}$ They fabricated a chip with vertical lateral flow of the antibody on the immune strip where the antigen-antibody reaction occurs and horizontal cross-flow for detection. Biotinylated capture antibody was used to increase the antigen-capturing ability upon binding to streptavidin.

A sandwich assay in the vertical column was created by a complex of biotinylated capture antibody, streptavidinfunctionalized cTnI antigen, and HRP-labeled detection antibody. As luminol flowed over the binding sites, a chemiluminometric signal was produced, which was detected by a detector placed in the chamber. The reported dynamic range of the biosensor was $0.1-100 \mathrm{ng} / \mathrm{mL}$, with an LOD of $0.02 \mathrm{ng} /$ $\mathrm{mL}$, and the detection time was nearly $20 \mathrm{~min}$.

Apart from using HRP, strategies using nanomaterial for signal amplification have also been used widely for chemiluminescence. Signal enhancement is achieved by nanocarriers loaded with excess amounts of enzyme molecules which, in turn, increases the number of signal-emitting molecules for a single recognition event. Many research groups use gold nanoparticles (AuNPs) or silver nanoparticles (AgNPs). ${ }^{35}$ To avoid an additional operation step when using AuNPs, Choi et al used two AuNP-antibody conjugates in a lateral flow assay. ${ }^{36}$ In 2010, Wu et al developed a poly(dimethylsiloxane) (PDMS)-gold composite-based biosensor in a colorimetric method for the detection of cTnI. Advantages of PDMS, such as ease of fabrication, thermal stability, and elasticity, 
were used in creating the biosensor. The ability of AuNPs to be functionalized with biomolecules such as antigens and enzymes makes them an ideal substrate. Therefore, the combination of PDMS and AuNPs makes it an excellent application for biosensors. The colorimetric technique has the advantage of convenience, as measurements are directly visible; however, its drawbacks include difficult labeling procedures as well as bulky and expensive techniques in comparison with other biosensing methods. ${ }^{37}$

Another optical technique used for troponin detection is chemiluminescence or electrochemiluminescence. It is termed electroluminescence when luminescence is emitted during an electrochemical reaction. Most of the techniques are labeled to generate electrochemical signals for amplification. In 2013, a group of researchers developed a label-free method using AuNPs functionalized with luminol, which acts as a carrier for the antibody. ${ }^{35}$ Streptavidin-biotin chemistry was used to ensure antibody-antigen binding, while the electrode was functionalized with luminol to generate electrochemiluminescence signals, forming hydrogen peroxide. The concentration of cTnI was determined from the intensity of electrochemiluminescence. Similar work was done in 2017 by Zhang et al, in which they achieved an LOD of $0.1 \mathrm{pg} / \mathrm{mL}$. They used the novel quenching effect of a glucose oxidase-folic acid- $\mathrm{PtCu}_{3}-\mathrm{Ab}_{2}$ bioconjugate with PAMAM and AuNPs to enhance the sensitivity of the biosensor using electrochemiluminescence. ${ }^{38}$

\section{SERS-based sensors}

SERS was introduced to improve on traditional Raman scattering by increasing the magnitude and sensitivity. ${ }^{39}$ A disadvantage of the Raman spectroscopy technique is its low accuracy, which is mainly due to low scattering efficiencies. This is overcome by SERS. Both work on the principle of the excitation of electrons from a roughened metallic surface which has been irradiated by a laser beam or any sort of electromagnetic radiation. Upon irradiation, electrons start oscillating and have the same wavelength as that of incident light. This process leads to an electric field enhancement as there is an addition of a secondary field to the already present incident electric field. On restricting the movement of these electrons, at a specific frequency of these oscillations, a resonance is observed in the incident field. This resonance helps in the detection of biomolecules near the confinement area or metallic surface by creating intense local fields. ${ }^{40}$ Nanoscale roughness on the surface of a metal causes an enhanced signal as biomolecules adsorb on to the surface. This target molecule enhances the Raman signal and can detect single biomolecule differences. Different methods of surface modification are used, such as nanoparticle deposition, metallic coating, or electrochemical roughening. The possibility for multiplexing and the sensitive detection technique have made SERS an interesting system for biosensing. A competitive immunoassay for cTnI and creatine kinase-MB detection based on the SERS technique was developed by Chon's research group. ${ }^{80} \mathrm{~A}$ magnetic bead surface was immobilized by specific monoclonal antibodies while two different nanotags were used for binding the target analyte. The reported detection time was $7 \mathrm{~min}$ between SERS nanotags and capture beads. The LOD for the SERS-based biosensor was $33.7 \mathrm{pg} / \mathrm{mL}$, which was more sensitive than electrochemiluminescent assays. ${ }^{41}$

An advantage of Raman spectroscopy over other optical techniques is that it overcomes the interference caused by the $-\mathrm{OH}$ bonds present in water. Since the principle of SERS is calculating fluorescence based on the vibration of electrons, the bands produced are very sharp and narrow compared to the wide bands produced by any other optical technique. These sharp bands contribute to the specificity of SERS. ${ }^{42}$

As discussed earlier in this subsection, owing to the specificity of the technique it can be used to analyze multiple samples or a microarray of different molecules at the same time, thus making it a high-throughput technique. However, there is still a challenge when using this technique for imaging in vivo as it uses metallic nanoparticles. These nanoparticles could turn out to be toxic over time. Thus, an approach using an alternative to these toxic nanoparticles, or coating them with a highly stable and biocompatible outer layer, must be taken. Another problem encountered while using SERS in vivo was the light, although, having a wavelength in the infrared region, it was not enough to penetrate human tissue. Better working probes and imaging systems could provide solutions to this problem..$^{40,41}$

\section{SPR-based sensors}

In 1983, SPR-based biosensors were first demonstrated by Liedberg et al for biosensing. ${ }^{43}$ Studies conducted since then have extensively explored the interactions between the biorecognition molecule and the target, and this has become a widely used optical technique for cardiac troponin detection. Apart from being used as a label-free biochemical assay, this technique has been used to quantify equilibrium constants in interactions of protein-protein, protein-DNA, and protein-ligand binding. In a basic SPR biosensor, one wall of the glass prism is immobilized with the biomolecule (antibody, ligand, etc.) and the target analyte flows across it. 
As the antigen-antibody binding interaction occurs, the intensity of light changes and quantifies the concentration of the target analyte. ${ }^{44}$ As it uses simple apparatus for detection, SPR is useful for rapid detection which does not require tedious labeling processes as in other optical techniques.

SPR-based sensors work on the principle of changes in resonance on irradiating the substrate with light waves. The shifts in the resonance curves reflect the movement of valence electrons when stimulated with light. An advantage of these sensors is that they are label free and thus do not require an additional labeling molecule. Researchers in the USA have developed a sensor that is sensitive to even attomolar concentrations of cardiac troponin in human biofluids (urine, blood, and serum). ${ }^{45}$ This unique sensor exploits the property of localized surface plasmon resonance (LSPR) of triangular gold nanoprisms. This electroluminescence-based sensor detects the cTnT levels in the fluid as soon as binding of the detection analyte occurs. The binding induces a change in the refractive index of the AuNPs, which creates a shift in the LSPR peaks. Amide bonds are used to stabilize the anti-cTnT binding to the gold nanoprisms. After structural optimization, the sensor displayed a sensitivity to concentrations as low as $250 \times 10^{-6} \mathrm{ng} / \mathrm{L}$ in human plasma. This LSPR-based sensor highlighted three important parameters that need to be considered when developing a similar sensor. The first is the sensing volume of the device; it was observed that a longer edge length of the gold triangular nanoprisms, i.e. a large sensing volume, resulted in greater sensitivity to cTnT. Second, the length of the SAM on top of the sensor plays a great role in increasing the sensitivity of the device. It is ideal to have many receptor molecules on the surface while having a low electrostatic/stearic repulsion caused by these molecules. Third is maintaining an optimum receptor-spacer ratio, in this paper they used a ratio of 8:2 for optimum binding of cTnT. However, there can be an overlap between the LSPR peaks in the near-infrared regions due to other biomolecules present on the surface. Thus, a material should be selected that does not have any peaks in the near-infrared region. Although this sensor displays a very high sensitivity to cTnT concentrations in symptomless or undiagnosed cases of myocardial infarction, it cannot quantify the cTnT concentration from single cell extracts. ${ }^{45,46}$

Tadepalli et al report a similar example of an LSPR sensor, ${ }^{47}$ which uses human troponin I binding peptide, immobilized on gold nanorods, as the detecting element. This sensor exploits the thiol group's affinity for gold. The novel feature of these sensors is that the whole set-up is on a paper substrate. Higher porosity, which directly corresponds to the excellent wicking properties of the detection analyte, high surface area, and cost-effectiveness, make a paper substrate easy to work with. This research also discusses the performance of sensors using antibody ${ }^{48,49}$ and using short peptides $^{50,51}$ as the detection element. The latter proved to be more sensitive and to have a lower LOD. A commercially available SPR system is the Biacore ${ }^{\mathrm{TM}} 4000$ instrument (GE Healthcare Life Sciences, Chicago, IL, USA). ${ }^{52}$ Conroy et al used this commercial system to test the specificity of the cTnI antibodies used in immunoassays. This high-throughput system has been widely used in developing SPR sensors for diagnosing AMI. ${ }^{52,53}$

One of the drawbacks of LSPR is its inability to detect large biomolecules, as the basic SPR structure penetrates to about $100 \mathrm{~nm}$ in the surrounding medium. It is also impossible to differentiate between changes in the refractive index at the surface versus the bulk solution. ${ }^{54}$ This reduces the sensing ability in complex solutions, such as blood. ${ }^{55-57}$

\section{Acoustic-based sensors}

Acoustic-based sensors work on the principle of mass estimation using a piezoelectric crystal. When the antigen-antibody complex forms on the surface of the electrode, the mass change leads to a shift in the frequency of the crystal, which generates an electric signal. These sensors are not commonly used, but their scope is increasing with advances in technology. Two subcategories are QCM- and SAW-based sensors, which are discussed in the following subsections.

\section{Quartz crystal microbalance}

The QCM is a type of sensor that exploits the piezoelectric properties of the quartz crystal that it contains. A QCM device measures the change in mass by changing the resonant frequency. This relationship between the mass and the resonant frequency is defined by the Sauerbrey equation:

$$
\Delta f=\frac{-2 f^{2} \Delta m}{A \rho v}
$$

where $A$ is the active area of the QCM electrode $\left(\mathrm{cm}^{2}\right), f$ is the resonant frequency of the $\mathrm{QCM}(\mathrm{Hz}), \Delta m$ is the change in the oscillating mass $(\mathrm{g}), \rho$ is the density of quartz $(\mathrm{g} /$ $\left.\mathrm{cm}^{3}\right)$, and $v$ is the shear wave velocity in the quartz $(\mathrm{cm} / \mathrm{s}) .^{58}$ Surface-modified QCM immunosensors are widely used for detecting cardiac troponin in a sample placed over the sensor. The electrode surface has an immobilized antibody and the mass loading of the sensor is achieved by antigenantibody binding. A microfluidic pumping system is used to deliver the reagents to the surface of the sensor. Wong et al reported a low-cost QCM-based sensor for the detection of cTnT. This sensor has an immobilized carboxylic polyvinyl 
Table 2 Summary of cardiac troponin sensors

\begin{tabular}{|c|c|c|c|c|}
\hline Description & Technique & LOD & Advantages of technique & Reference \\
\hline $\begin{array}{l}\text { Three-electrode cell using a GCE coated } \\
\text { with porous graphene oxide; human } \\
\text { troponin I as working electrode }\end{array}$ & Electrochemical & $0.07 \mathrm{ng} / \mathrm{mL}$ & $\begin{array}{l}\text { Inexpensive, label free; uses } \\
\text { graphene, which has good } \\
\text { electrochemical behavior and large } \\
\text { active surface area; good selectivity } \\
\text { and high sensitivity }\end{array}$ & 18 \\
\hline $\begin{array}{l}\text { AuNPs are deposited on a GCE, } \\
\text { peptide probe is added to electrode; EIS } \\
\text { response should increase with increasing } \\
\text { concentration of troponin I }\end{array}$ & Electrochemical & $2.4 \mathrm{pg} / \mathrm{mL}$ & $\begin{array}{l}\text { Using an AuNP-modified GCE } \\
\text { reduces background EIS signal and } \\
\text { enhances EIS response; simple, } \\
\text { sensitive, fast }\end{array}$ & 62 \\
\hline $\begin{array}{l}\text { Uses MIP technology with a three- } \\
\text { electrode system }\end{array}$ & Electrochemical & $0.027 \mathrm{nM}$ & $\begin{array}{l}\text { Detection time of } 5 \text { min, can } \\
\text { be used without much sample } \\
\text { pretreatment, simple, low cost of } \\
\text { preparation, label free }\end{array}$ & 20 \\
\hline $\begin{array}{l}\text { SPR film is gold film evaporated on a } \\
\text { glass slide modified by hollow AuNPs } \\
\text { and immobilized with antibodies that } \\
\text { target troponin }\end{array}$ & SPR & $1.25 \mathrm{ng} / \mathrm{mL}$ & $\begin{array}{l}\text { Gold film amplifies SPR response; } \\
\text { fast, accurate, and straightforward } \\
\text { detection }\end{array}$ & 63 \\
\hline $\begin{array}{l}\text { Gold sensor chip and prism-based SPR } \\
\text { biosensor; experiments using direct and } \\
\text { sandwich assays }\end{array}$ & SPR & $\begin{array}{l}5 \mathrm{ng} / \mathrm{mL} \text { for } \\
\text { standard sandwich } \\
\text { assay; } 0.5 \mathrm{ng} / \\
\mathrm{mL} \text { using AuNP } \\
\text { detector antibodies }\end{array}$ & $\begin{array}{l}\text { Using the regeneration method, } \\
\text { the SPR sensor can be reused for } \\
\text { multiple samples; rapid response, } \\
\text { can provide real-time data }\end{array}$ & 64 \\
\hline $\begin{array}{l}\text { AuNPs are functionalized and used as } \\
\text { label }\end{array}$ & $\begin{array}{l}\text { Optical } \\
\text { (chemiluminescence or } \\
\text { electrochemiluminescence) }\end{array}$ & $0.06 \mathrm{ng} / \mathrm{mL}$ & $\begin{array}{l}\text { High sensitivity, low background, } \\
\text { simple }\end{array}$ & 65 \\
\hline $\begin{array}{l}\text { AuNPs are applied to PDMS film then } \\
\text { covered with antibody. After cTnl is } \\
\text { captured, a silver solution is dropped } \\
\text { on to the sensor. The silver solution } \\
\text { undergoes reduction and causes color } \\
\text { changes }\end{array}$ & Optical (colorimetric) & $0.01 \mathrm{ng} / \mathrm{mL}$ & $\begin{array}{l}\text { Practical and easy to operate and } \\
\text { fabricate }\end{array}$ & 65 \\
\hline $\begin{array}{l}\text { Multianalyte detection of CRP and cTnl } \\
\text { using microfluidic networks in human } \\
\text { plasma }\end{array}$ & Optical (fluorescence) & $30 \mathrm{ng} / \mathrm{mL}$ & $\begin{array}{l}\text { Low analyte volume }(\mathrm{I} \mu \mathrm{L}) \text {, } \\
\text { multianalyte detection for better } \\
\text { screening of markers in multiple } \\
\text { samples }\end{array}$ & 66 \\
\hline $\begin{array}{l}\text { Fluoro-microbead guiding chip-based } \\
\text { sandwich immunoassay for detection of } \\
\text { cTnl }\end{array}$ & Optical (fluorescence) & $0.1 \mathrm{ng} / \mathrm{mL}$ & $\begin{array}{l}\text { Chip supports four immunosensing } \\
\text { regions which can test four } \\
\text { different concentrations of cTnl } \\
\text { simultaneously; ease of signal } \\
\text { quantification }\end{array}$ & 67 \\
\hline $\begin{array}{l}\text { Multianalyte detection using } \\
\text { chemiluminescent immunoassay; } \\
\text { ultrasound waves are used to enhance } \\
\text { immobilization of the capture probe }\end{array}$ & ELISA; chemiluminometric & $4.3 \times 10^{4} \mathrm{ng} / \mathrm{mL}$ & $\begin{array}{l}\text { Short incubation time, } \\
\text { prototype for automated } \\
\text { robotic measurement of cardiac } \\
\text { biomarkers, disposable }\end{array}$ & 68 \\
\hline $\begin{array}{l}\text { Phage-displayed peptides for detection } \\
\text { of cTnl. ELISA results indicate binding } \\
\text { interaction between troponin antigen } \\
\text { and phage-displayed peptide }\end{array}$ & ELISA & $0.002 \mathrm{ng} / \mathrm{mL}$ & $\begin{array}{l}\text { Novel phage display technology } \\
\text { for monitoring of cardiac cells in } \\
\text { a culture in addition to detection } \\
\text { of cTnl }\end{array}$ & 69 \\
\hline $\begin{array}{l}\text { Chemiluminometric biosensor system } \\
\text { coupled with cross-flow chromatography } \\
\text { to enable binding of antigen-capture } \\
\text { probe and signal generation }\end{array}$ & ELISA & $0.01 \mathrm{ng} / \mathrm{mL}$ & $\begin{array}{l}\text { Rapid (detection time } 30 \mathrm{~s} \text { ), } \\
\text { biotin-streptavidin complex- } \\
\text { enhanced signal response, reduced } \\
\text { antibody concentration needed for } \\
\text { detection }\end{array}$ & 34 \\
\hline $\begin{array}{l}\text { Streptavidin-terminated SAM of } \\
\text { carboxymethyldextran based on SPR } \\
\text { for detection of cTnT with the help of } \\
\text { immobilized monoclonal anti-troponin T } \\
\text { antibodies }\end{array}$ & SPR & $0.01 \mathrm{ng} / \mathrm{mL}$ & $\begin{array}{l}\text { Fast, sensitive, and specific for } \\
\text { troponin in human sera; label-free } \\
\text { analysis }\end{array}$ & 70 \\
\hline
\end{tabular}


Table 2 (Continued)

\begin{tabular}{|c|c|c|c|c|}
\hline Description & Technique & LOD & Advantages of technique & Reference \\
\hline $\begin{array}{l}\text { SPR sensor developed on a commercial } \\
\text { surface plasmon resonance device. } \\
\text { Troponin receptor molecules are } \\
\text { covalently immobilized using a thiol } \\
\text { linker using cysteamine molecules }\end{array}$ & SPR & $0.05 \mathrm{ng} / \mathrm{mL}$ & $\begin{array}{l}\text { Cost-effective, reusable sensor; } \\
\text { SDS surfactant used for } \\
\text { regeneration of immunosensor; no } \\
\text { dilution of serum required }\end{array}$ & 71 \\
\hline $\begin{array}{l}\text { Troponin detection using an immobilized } \\
\text { monoclonal antibody of cTnT on the } \\
\text { surface of thin gold film }\end{array}$ & SPR & $0.068 \mathrm{ng} / \mathrm{mL}$ & $\begin{array}{l}\text { Monoclonal antibody created using } \\
\text { a peptide epitope with a protein- } \\
\text { based screening method; enhances } \\
\text { sensitivity of sensor }\end{array}$ & 72 \\
\hline $\begin{array}{l}\text { Optomagnetic immunoassay using } \\
\text { magnetic nanoparticles, which are } \\
\text { magnetically actuated and detected } \\
\text { optically. Multiplexed sensor for } \\
\text { detection of multiple analytes }\end{array}$ & Optomagnetic & $0.0117 \mathrm{ng} / \mathrm{mL}$ & $\begin{array}{l}\text { Rapid, sensitive, low cost, } \\
\text { disposable kit; one-step assays can } \\
\text { be developed using this technology }\end{array}$ & 73 \\
\hline $\begin{array}{l}\text { Detection of cTnl using a combinatorial } \\
\text { technique of optical and magnetic } \\
\text { technology. Sandwich immunoassay using } \\
\text { superparamagnetic nanoparticles coupled } \\
\text { with optical detection of generated signal }\end{array}$ & Optomagnetic & $0.03 \mathrm{ng} / \mathrm{mL}$ & Rapid, sensitive, and point of care & 74 \\
\hline $\begin{array}{l}\text { Simultaneous detection of CRP and cTnl } \\
\text { using PDMS-AuNPs }\end{array}$ & Impedimetric & $0.01 \mathrm{ng} / \mathrm{mL}$ & $\begin{array}{l}\text { Low LOD, low sample volume } \\
(I \mu L)\end{array}$ & 66 \\
\hline $\begin{array}{l}\text { Screen-printed electrodes coupled with } \\
\text { streptavidin polystyrene microspheres } \\
\text { for detection of cTnT }\end{array}$ & Impedimetric & $0.2 \mathrm{ng} / \mathrm{mL}$ & $\begin{array}{l}\text { Ideal for miniaturized systems, } \\
\text { disposable }\end{array}$ & 75 \\
\hline $\begin{array}{l}\text { Quantum dot-based technique which } \\
\text { uses an LCW platform to capture } \\
\text { fluorescence. Protein A is bound to the } \\
\text { capture probe for enhanced sensitivity }\end{array}$ & FRET & $55 \mathrm{nM}$ & $\begin{array}{l}\text { LCW platform decreases the } \\
\text { stearic hindrance of immobilized } \\
\text { capture sites; high efficiency }\end{array}$ & 76 \\
\hline $\begin{array}{l}\text { Homogeneous sandwich assay using } \\
\text { quenching property of AuNPs. } \\
\text { Simultaneous interaction of dye } \\
\text { molecules and AuNPs enhances the } \\
\text { signal of the immunoassay for detection } \\
\text { of cTnT }\end{array}$ & FRET & $0.7 \mathrm{ng} / \mathrm{mL}$ & $\begin{array}{l}\text { High efficiency; overall enhanced } \\
\text { signal }\end{array}$ & 77 \\
\hline $\begin{array}{l}\text { Polypyrrole-based potentiometric } \\
\text { biosensor for broad-spectrum detection } \\
\text { of various analytes including troponin I }\end{array}$ & Potentiometric & $0.01 \mathrm{ng} / \mathrm{mL}$ & $\begin{array}{l}\text { Rapid, ultrasensitive, reproducible, } \\
\text { wide dynamic range }\end{array}$ & 78 \\
\hline $\begin{array}{l}\text { Multiplexed detection of cTnT and cTnl } \\
\text { on a disposable and flexible impedimetric } \\
\text { biosensor. } \mathrm{ZnO} \text { nanostructures enhance } \\
\text { the signal of the electrode }\end{array}$ & Impedimetric & I pg/mL & $\begin{array}{l}\text { Multiplexing, low LOD, signal well } \\
\text { above noise threshold }\end{array}$ & 17 \\
\hline
\end{tabular}

Abbreviations: LOD, limit of detection; GCE, glassy carbon electrode; AuNP, gold nanoparticle; EIS, electrochemical impedance spectroscopy; MIP, molecularly imprinted polymer; SPR, surface plasmon resonance; PDMS, poly(dimethylsiloxane); CRP, C-reactive protein; cTnl, cardiac troponin I; ELISA, enzyme-linked immunosorbent assay; SAM, self-assembled monolayer; cTnT, cardiac troponin T; SDS, sodium dodecyl sulfate; LCW, liquid-core waveguide; FRET, fluorescence resonance energy transfer.

chloride layer, which enhances its sensitivity for detection. An electrical signal generated by the frequency shift indicates the amount of mass accumulating over the surface. The LOD for this sensor is $5 \mathrm{ng} / \mathrm{mL} .{ }^{59}$ Another sensor, reported by Wu et al, involves immobilization of a short synthetic peptide on the surface of the QCM-based biosensor. This peptide has an affinity for cTnI. A phage molecule was used to display this molecule to enable the cTnI molecules to bind to it. Both QCM and EIS techniques were explored in this paper. The LOD is $0.11 \mu \mathrm{g} / \mathrm{mL}$ when the sensor response is measured using QCM. This is lower than the EIS calculations, which is due to a lower background noise level in QCM than in EIS. However, there are drawbacks to using the QCM technique. It cannot be integrated into a device easily as it requires strict pressure and temperature control. ${ }^{60}$

\section{SAW-based sensors}

SAW-based sensors operate in a similar fashion to QCM sensors. A SAW-based sensor consists of interdigitated transducer electrodes with a piezoelectric crystal surface coupled between them. The transducers convert the electrical signal into a polarized transversal acoustic wave, which 
travels across the piezoelectric crystal. Mass accumulation on this piezoelectric crystal leads to a shift in the frequency of the generated acoustic wave and allows for biosensing. SAW sensors have many variations, including RayleighSAW, Lamb-wave sensors, and Love-wave sensors. Lee et al demonstrated a Love-wave SAW sensor for the detection of cTnI. The formation of complexes between the antibody immobilized using AuNPs and cTnI antigen present in the human serum drives the response of the sensor. This sensor represents a prototype for using acoustic wave-based sensors for biosensing; with further tweaking of the frequency and other parameters, the authors believe that this device could be successfully used for the clinical diagnosis of AMI ${ }^{61}$

The cardiac troponin sensors described in this paper and some other sensors are summarized in Table 2.

\section{Conclusion and future work}

Researchers in the medical field have pointed out the need to develop sensing platforms to detect cardiac troponins in the interest of creating point-of-care diagnostics for the detection of AMI. In this review, recent developments of different types of biosensors have been summarized with regard to various techniques along with their merits and drawbacks. A few techniques for biosensing, such as optical-based techniques, have already been introduced to the market, and newer techniques are still evolving. Some drawbacks of optical-based techniques such as colorimetric, fluorescence, and SPR methods include the need for bulky equipment and labeling, and their low sensitivity. Electrochemical techniques are widely used owing to their ease in handling, portability, and scope for miniaturization. The aim of developing different types of biosensors is to enable them to be translated into portable, handheld devices which can be used with ease and deliver laboratory-grade sensing performance. Having summarized various techniques, key challenges still need to be addressed, such as increasing sensitivity, miniaturization, multiplexing, and reducing detection times. Researchers should try to incorporate methods to increase stability and reduce the effects of interferents that generate false-positive results. Cross-reactivity remains a major concern in immunology-based diagnostic assays. In addition, developments in using circulatory micro-RNA (miRNA) as biomarkers for the diagnosis of AMI have reported by Sayed et al. In their study, three miRNAs out of 20 were associated with percutaneous coronary intervention, which suggests that they could also be used as biomarkers for prognosis of AMI. However, part of the study is yet to be published and it is awaiting clinical trials. Cardiac troponin sensors coupled with circulating miRNA technology may provide a better diagnostic platform for AMI. ${ }^{79}$

The performance of existing biosensors could be enhanced by improving the analytical chemistry between biomolecules, through surface-modification techniques, or by integrating several detection techniques. New approaches, such as integrating miniaturization and smart detection, could make point-of-care testing more significant. Considering all the factors required to improve point-of-care devices, there is a lot of scope for improvement.

\section{Disclosure}

The authors report no conflicts of interest in this work.

\section{References}

1. Thygesen K, Alpert JS, White HD; Joint ESC/ACCF/AHA/WHF Task Force for the Redefinition of Myocardial Infarction. Universal definition of myocardial infarction. Eur Heart J. 2007;28(20):2525-2538.

2. Hamm CW, Goldmann BU, Heeschen C, Kreymann G, Berger J, Meinertz T. Emergency room triage of patients with acute chest pain by means of rapid testing for cardiac troponin T or troponin I. N Engl J Med. 1997;337(23):1648-1653.

3. Shah AS, Anand A, Sandoval Y, et al. High-sensitivity cardiac troponin I at presentation in patients with suspected acute coronary syndrome: a cohort study. Lancet. 2015;386(10012):2481-2488.

4. Christenson RH, Azzazy HME. Cardiac point of care testing: a focused review of current National Academy of Clinical Biochemistry guidelines and measurement platforms. Clin Biochem. 2009;42(3):150-157.

5. Neumann J, Sörensen NA, Schwemer T, et al. Diagnosis of myocardial infarction using a high-sensitivity troponin I 1-hour algorithm. JAMA Cardiol. 2016;1(4):397-404.

6. Roffi M, Patrono C, Collet J-P, et al. 2015 ESC Guidelines for the management of acute coronary syndromes in patients presenting without persistent ST-segment elevation: Task Force for the Management of Acute Coronary Syndromes in Patients Presenting without Persistent ST-Segment Elevation of the European Society of Cardiology (ESC). Eur Heart J. 2016;37(3):267-315.

7. Keller T, Zeller T, Peetz D, et al. Sensitive troponin I assay in early diagnosis of acute myocardial infarction. N Engl J Med. 2009;361(9): 868-877.

8. McLaurin MD, Apple FS, Voss EM, Herzog CA, Sharkey SW. Cardiac troponin I, cardiac troponin T, and creatine kinase MB in dialysis patients without ischemic heart disease: evidence of cardiac troponin T expression in skeletal muscle. Clin Chem. 1997;43(6):976-982.

9. Müller-Bardorff M, Hallermayer K, Schröder A, et al. Improved troponin T ELISA specific for cardiac troponin T isoform: assay development and analytical and clinical validation. Clin Chem. 1997;43(3):458-466.

10. Chew DP, Zeitz C, Worthley M, et al. Randomized comparison of highsensitivity troponin reporting in undifferentiated chest pain assessment. Circ Cardiovasc Qual Outcomes. 2016;9(5):542-553.

11. Daubert MA, Jeremias A. The utility of troponin measurement to detect myocardial infarction: review of the current findings. Vasc Health Risk Manag. 2010;6:691-699.

12. Bhatnagar D, Kaur I, Kumar A. Ultrasensitive cardiac troponin I antibody based nanohybrid sensor for rapid detection of human heart attack. Int J Biol Macromol. 2017;95 (Suppl C):505-510.

13. Bertsch T, Bleuel H, Deschl U, Rebel W. A new sensitive cardiac Troponin $\mathrm{T}$ rapid test $\left(\mathrm{TROPT}^{\circledR}\right)$ for the detection of experimental acute myocardial damage in rats. Exp Toxicol Pathol. 1999;51(6): $565-569$. 
14. Lomant AJ, Fairbanks G. Chemical probes of extended biological structures: Synthesis and properties of the cleavable protein crosslinking reagent $[35 \mathrm{~S}]$ dithiobis(succinimidyl propionate). $\mathrm{J} \mathrm{Mol} \mathrm{Biol.}$ 1976;104(1):243-261.

15. Swaim CL, Smith JB, Smith DL. Unexpected products from the reaction of the synthetic cross-linker 3,3'-dithiobis(sulfosuccinim idyl propionate), DTSSP with peptides. J Am Soc Mass Spectrom. 2004;15(5):736-749.

16. Choi SY, Lee Y-J, Park YS, Ha K, Yoon KB. Monolayer assembly of zeolite crystals on glass with fullerene as the covalent linker. JAm Chem Soc. 2000;122(21):5201-5209.

17. Radha Shanmugama N, Muthukumarb S, Chaudhry S, Anguianao J, Prasad S. Ultrasensitive nanostructure sensor arrays on flexible substrates for multiplexed and simultaneous electrochemical detection of a panel of cardiac biomarkers. Biosens Bioelectron. 2017;89:764-772.

18. Kazemi SH, Ghodsi E, Abdollahi S, Nadri S. Porous graphene oxide nanostructure as an excellent scaffold for label-free electrochemical biosensor: detection of cardiac troponin I. Mater Sci Eng C Mater Biol Appl. 2016;69 (Suppl C):447-452.

19. Moretti M, Sisti D, Rocchi MB, Delprete E. CLSI EP17-A protocol: a useful tool for better understanding the low end performance of total prostate-specific antigen assays. Clin Chim Acta. 2011;412(11-12): $1143-1145$

20. Zuo J, Zhao X, Ju X, et al. A new molecularly imprinted polymer (MIP)based electrochemical sensor for monitoring cardiac troponin I (cTnI) in the serum. Electroanalysis. 2016;28(9):2044-2049.

21. Gomes-Filho SLR, Dias ACMS, Silva MMS, Silva BVM, Dutra RF. A carbon nanotube-based electrochemical immunosensor for cardiac troponin T. Microchem J. 2013;109:10-15.

22. Akter R, Jeong B, Lee Y-M, Choi J-S, Rahman MA. Femtomolar detection of cardiac troponin I using a novel label-free and reagent-free dendrimer enhanced impedimetric immunosensor. Biosens Bioelectron. 2017;91 (Suppl C):637-643.

23. Abbott Point of Care, USA. i-STAT handheld; 1997. https://www. pointofcare.abbott/us/en/offerings/istat/istat-handheld. Accessed October 26, 2017.

24. Purvis D, Leonardova O, Farmakovsky D, Cherkasov V. An ultrasensitive and stable potentiometric immunosensor. Biosens Bioelectron. 2003;18(11):1385-1390.

25. Chua JH, Chee R-E, Agarwal A, Wong SM, Zhang G-J. Label-free electrical detection of cardiac biomarker with complementary metaloxide semiconductor-compatible silicon nanowire sensor arrays. Anal Chem. 2009;81(15):6266-6271.

26. Fan X, White IM, Shopova SI, Zhu H, Suter JD, Sun Y. Sensitive optical biosensors for unlabeled targets: a review. Anal Chim Acta. 2008;620(1-2):8-26.

27. Coons AH, Creech HJ, Jones RN. Immunological properties of an antibody containing a fluorescent group. Proc Soc Exp Biol Med. 1941;47(2):200-202.

28. Kar P, Pandey A, Greer JJ, Shankar K. Ultrahigh sensitivity assays for human cardiac troponin I using $\mathrm{TiO} 2$ nanotube arrays. Lab Chip. 2012;12(4):821-828.

29. Cox WG, Singer VL. Fluorescent DNA hybridization probe preparation using amine modification and reactive dye coupling. Biotechniques. 2004;36(1):114-122.

30. Diware MS, Cho HM, Chegal W, et al. Ultrasensitive, label-free detection of cardiac biomarkers with optical SIS sensor. Biosens Bioelectron. 2017;87 (Suppl C):242-248.

31. Tan Y, Wang Y, Li M, Ye X, Wu T, Li C. Enhanced photoelectrochemical immunosensing of cardiac troponin I based on energy transfer between $\mathrm{N}$-acetyl-L-cysteine capped CdAgTe quantum dots and dodecahedral Au nanoparticles. Biosens Bioelectron. 2017;91 (Suppl C):741-746.

32. Thermo Fisher Scientific. Overview of ELISA; 2016. https://www. thermofisher.com/us/en/home/life-science/protein-biology/proteinbiology-learning-center/protein-biology-resource-library/pierceprotein-methods/overview-elisa.html. Accessed April 12, 2017.
33. Wu KH, Mo XM, Zhou B, et al. Cardiac potential of stem cells from whole human umbilical cord tissue. J Cell Biochem. 2009;107(5):926-932.

34. Cho I-H, Paek E-H, Kim Y-K, Kim J-H, Paek S-H. Chemiluminometric enzyme-linked immunosorbent assays (ELISA)-on-a-chip biosensor based on cross-flow chromatography. Anal Chim Acta. 2009;632(2):247-255.

35. Li F, Yu Y, Cui H, Yang D, Bian Z. Label-free electrochemiluminescence immunosensor for cardiac troponin I using luminol functionalized gold nanoparticles as a sensing platform. Analyst. 2013;138(6):1844-1850.

36. Choi DH, Lee SK, Oh YK, et al. A dual gold nanoparticle conjugatebased lateral flow assay (LFA) method for the analysis of troponin I. Biosens Bioelectron. 2010;25(8):1999-2002.

37. Wu W-Y, Bian Z-P, Wang W, Wang W, Zhu J-J. PDMS gold nanoparticle composite film-based silver enhanced colorimetric detection of cardiac troponin I. Sens Actuators B Chem. 2010;147(1):298-303.

38. Zhang L, Xiong C, Wang H, Yuan R, Chai Y. A sensitive electrochemiluminescence immunosensor for cardiac troponin I detection based on dual quenching of the self-enhanced $\mathrm{Ru}$ (II) complex by folic acid and in situ generated oxygen. Sens Actuators B Chem. 2017;241 (Suppl C):765-772.

39. Campion A, Kambhampati P. Surface-enhanced Raman scattering. Chem Soc Rev. 1998;27(4):241-250.

40. Vo-Dinh T. Nanobiosensing using plasmonic nanoprobes. IEEE J Sel Top Quantum Electron. 2008;14(1):198-205.

41. Zhang Y, Hong H, Myklejord DV, Cai W. Molecular imaging with SERS-active nanoparticles. Small. 2011;7(23):3261-3269.

42. Cui Y, Ren B, Yao J-L, Gu R-A, Tian Z-Q. Synthesis of $\mathrm{Ag}_{\text {core }} \mathrm{Au}_{\text {shell }}$ bimetallic nanoparticles for immunoassay based on surface-enhanced Raman spectroscopy. J Phys Chem B. 2006;110(9):4002-4006.

43. Liedberg B, Nylander C, Lunström I. Surface plasmon resonance for gas detection and biosensing. Sensors and Actuators. 1983;4 (Suppl C): 299-304.

44. Englebienne P, Van Hoonacker A, Verhas M. Surface plasmon resonance: principles, methods and applications in biomedical sciences. Spectroscopy 2003;17(2-3):255-273.

45. Liyanage T, Sangha A, Sardar R. Achieving biosensing at attomolar concentrations of cardiac troponin $\mathrm{T}$ in human biofluids by developing a label-free nanoplasmonic analytical assay. Analyst. 2017;142(13):2442-2450.

46. Kaushik A, Vasudev A, Arya SK, Pasha SK, Bhansali S. Recent advances in cortisol sensing technologies for point-of-care application. Biosens Bioelectron. 2014;53:499-512.

47. Tadepalli S, Kuang Z, Jiang Q, et al. Peptide functionalized gold nanorods for the sensitive detection of a cardiac biomarker using plasmonic paper devices. Sci Rep. 2015;5:16206.

48. Casas J, Venkataramasubramani M, Wang Y, Tang L. Replacement of cetyltrimethylammoniumbromide bilayer on gold nanorod by alkanethiol crosslinker for enhanced plasmon resonance sensitivity. Biosens Bioelectron. 2013;49 (Suppl C):525-530.

49. Tang L, Casas J. Quantification of cardiac biomarkers using label-free and multiplexed gold nanorod bioprobes for myocardial infarction diagnosis. Biosens Bioelectron. 2014;61 (Suppl C):70-75.

50. Wei F, Zhang D, Halas NJ, Hartgerink JD. Aromatic amino acids providing characteristic motifs in the Raman and SERS spectroscopy of peptides. J Phys Chem B. 2008;112(30):9158-9164.

51. Nergiz SZ, Gandra N, Farrell ME, Tian L, Pellegrino PM, Singamaneni S. Biomimetic SERS substrate: peptide recognition elements for highly selective chemical detection in chemically complex media. $J$ Mater Chem A. 2013;1(22):6543-6549.

52. GE Healthcare Life Sciences. Biacore 4000 surface plasmon resonance system. 2012. https://www.gelifesciences.com/shop/protein-analysis/ spr-label-free-analysis/systems/biacore-4000-surface-plasmonresonance-system-p-06144. Accessed December 31, 2017.

53. Conroy PJ, O'Kennedy RJ, Hearty S. Cardiac troponin I: a case study in rational antibody design for human diagnostics. Protein Eng Des Sel. 2012;25(6):295-305.

54. Nenninger GG, Tobiška P, Homola J, Yee SS. Long-range surface plasmons for high-resolution surface plasmon resonance sensors. Sens Actuators B Chem. 2001;74(1-3):145-151. 
55. Hastings JT, Guo J, Keathley PD, et al. Optimal self-referenced sensing using long- and short- range surface plasmons. Opt Express. 2007;15(26):17661-17672.

56. Slavík R, Homola J. Ultrahigh resolution long range surface plasmonbased sensor. Sens Actuators B Chem. 2007;123(1):10-12.

57. Guo J, Keathley PD, Hastings JT. Dual-mode surface-plasmon-resonance sensors using angular interrogation. Opt Lett. 2008;33(5):512-514.

58. Van Quy N, Minh VA, Van Luan N, Hung VN, Van Hieu N. Gas sensing properties at room temperature of a quartz crystal microbalance coated with ZnO nanorods. Sens Actuators B Chem. 2011;153(1):188-193.

59. Wong-ek K, Chailapakul O, Nuntawong N, Jaruwongrungsee K, Tuantranont A. Cardiac troponin $\mathrm{T}$ detection using polymers coated quartz crystal microbalance as a cost-effective immunosensor. Biomed Tech (Berl). 2010;55(5):279-284.

60. Wu J, Cropek DM, West AC, Banta S. Development of a troponin I biosensor using a peptide obtained through phage display. Anal Chem. 2010;82(19):8235-8243.

61. Lee J, Choi Y-S, Lee Y, et al. Sensitive and simultaneous detection of cardiac markers in human serum using surface acoustic wave immunosensor. Anal Chem. 2011;83(22):8629-8635.

62. Wang B, Jing R, Qi H, Gao Q, Zhang C. Label-free electrochemical impedance peptide-based biosensor for the detection of cardiac troponin I incorporating gold nanoparticles modified carbon electrode. J Electroanal Chem. 2016;781 (Suppl C):212-217.

63. Wu Q, Sun Y, Zhang D, et al. Ultrasensitive magnetic field-assisted surface plasmon resonance immunoassay for human cardiac troponin I. Biosens Bioelectron. 2017;96 (Suppl C):288-293.

64. Pawula M, Altintas Z, Tothill IE. SPR detection of cardiac troponin $\mathrm{T}$ for acute myocardial infarction. Talanta. 2016;146 (Suppl C): 823-830.

65. Abdolrahim M, Rabiee M, Alhosseini SN, Tahriri M, Yazdanpanah S, Tayebi L. Development of optical biosensor technologies for cardiac troponin recognition. Anal Biochem. 2015;485 (Suppl C):1-10.

66. Wolf M, Juncker D, Michel B, Hunziker P, Delamarche E. Simultaneous detection of $\mathrm{C}$-reactive protein and other cardiac markers in human plasma using micromosaic immunoassays and self-regulating microfluidic networks. Biosens Bioelectron. 2004;19(10):1193-1202.

67. Song SY, Han YD, Kim K, Yang SS, Yoon HC. A fluoro-microbead guiding chip for simple and quantifiable immunoassay of cardiac troponin I (cTnI). Biosens Bioelectron. 2011;26(9):3818-3824.
68. Torabi F, Mobini Far HR, Danielsson B, Khayyami M. Development of a plasma panel test for detection of human myocardial proteins by capillary immunoassay. Biosens Bioelectron. 2007;22(7):1218-1223.

69. Park JP, Cropek DM, Banta S. High affinity peptides for the recognition of the heart disease biomarker troponin I identified using phage display. Biotechnol Bioeng. 2010;105(4):678-686.

70. Dutra RF, Kubota LT. An SPR immunosensor for human cardiac troponin T using specific binding avidin to biotin at carboxymethyldextranmodified gold chip. Clin Chim Acta. 2007;376(1-2):114-120.

71. Dutra RF, Mendes RK, da Silva V, Kubota LT. Surface plasmon resonance immunosensor for human cardiac troponin $\mathrm{T}$ based on selfassembled monolayer. J Pharm Biomed Anal. 2007;43(5):1744-1750.

72. Kwon Y-C, Kim M-G, Kim E-M, et al. Development of a surface plasmon resonance-based immunosensor for the rapid detection of cardiac troponin I. Biotechnol Lett. 2011;33(5):921-927.

73. Bruls DM, Evers TH, Kahlman JAH, et al. Rapid integrated biosensor for multiplexed immunoassays based on actuated magnetic nanoparticles. Lab Chip. 2009;9(24):3504-3510.

74. Dittmer WU, Evers TH, Hardeman WM, et al. Rapid, high sensitivity, point-of-care test for cardiac troponin based on optomagnetic biosensor. Clin Chim Acta. 2010;411(11-12):868-873.

75. Silva BVM, Cavalcanti IT, Mattos AB, Moura P, Sotomayor MDPT, Dutra RF. Disposable immunosensor for human cardiac troponin $\mathrm{T}$ based on streptavidin-microsphere modified screen-printed electrode. Biosens Bioelectron. 2010;26(3):1062-1067.

76. Stringer RC, Hoehn D, Grant SA. Quantum dot-based biosensor for detection of human cardiac troponin I using a liquid-core waveguide. IEEE Sens J. 2008;8(3):295-300.

77. Mayilo S, Kloster MA, Wunderlich M, et al. Long-range fluorescence quenching by gold nanoparticles in a sandwich immunoassay for cardiac troponin T. Nano Lett. 2009;9(12):4558-4563.

78. Pedrero M, Campuzano S, Pingarrón JM. Electrochemical biosensors for the determination of cardiovascular markers: a review. Electroanalysis. 2014;26(6):1132-1153.

79. Sayed ASM, Xia K, Yang TL, Peng J. Circulating microRNAs: a potential role in diagnosis and prognosis of acute myocardial infarction. Dis Markers. 2013;35(5):561-566.

80. Chon H, Lee S, Yoon S-Y, et al. SERS-based competitive immunoassay of troponin I and CK-MB markers for early diagnosis of acute myocardial infarction. Chem Commun. 2014;50(9):1058-1060.
Advanced Health Care Technologies

\section{Publish your work in this journal}

Advanced Health Care Technologies is an international, peer reviewed open access journal that provides a unique forum for articles on point-of-care, health care diagnostics and treatment, bioengineering, biotechnology, biosensing, electronics, clinical/medical science, chemical engineering, materials science, regenerative medicine, micro-/
Dovepress

nano-technologies, and methods and applications for nanoscience and nanotechnology. The manuscript management system is completely online and includes a very quick and fair peer review system, which is all easy to use. Visit http://www.dovepress.com/testimonials.php to read real quotes from published authors. 